\title{
Equilibrium Exchange Rate Determination and Multiple Structural Changes
}

\author{
Mario Cerrato*, Hyunsok Kim*1 and Ronald MacDonald* \\ University of Glasgow, Department of Economics, Adam Smith building.
}

May 13, 2010

\footnotetext{
${ }^{1}$ Corresponding author Hyunsok Kim University of Glasgow, Department of Economics, Adam Smith building (E-mail: h.kim.3@research.gla.ac.uk); Mario Cerrato (E-mail: m.cerrato@lbss.gla.ac.uk) and Ronald MacDonald (E-mail: r.macdonald@lbss.gla.ac.uk). We would like to thank Karim Abadir for his helpful comments and suggestions.
} 


\begin{abstract}
The large appreciation and depreciation of the US dollar in the 1980s stimulated an important debate on the usefulness of unit root tests in the presence of structural breaks. In this paper, we propose a simple model to describe the evolution of the real exchange rate. We then propose a more general smooth transition (STR) function than has hitherto been employed, which is able to capture structural changes along the (long-run) equilibrium path, and show that this is consistent with our economic model. Our framework allows for a gradual adjustment between regimes and allows for underand/or over-valued exchange rate adjustments. Using monthly and quarterly data for up to twenty OECD countries, we apply our methodology to investigate the univariate time series properties of CPI-based real exchange rates with both the U.S. dollar and German mark as the numeraire currencies. The empirical results show that, for more than half of the quarterly series, the evidence in favour of the stationarity of the real exchange rate was clearer in the sub-sample period post-1980.

JEL Classification: C16, C22, F31
\end{abstract}

Keywords: Unit root tests, structural breaks, purchasing power parity 


\section{Introduction}

The time series properties of real and nominal exchange rates has been an enduring research topic during the post Bretton Woods period. The so-called PPP puzzle of Rogoff (1996) suggests that the relatively slow mean reversion of real exchange rates is too slow to be consistent with purchasing power parity (PPP), even when panel unit root methods are used (see MacDonald (2007) for an overview). Recent work by, for example, Papell (2002) and Sollis (2005) demonstrates that the lack of evidence in favor of PPP might be due to the existence of structural breaks as a result of the dramatic behaviour of the US dollar in the 1980s (the so-called Lothian effect). However, their results show rather weak evidence when the US Dollar is assumed to be the base currency.

In this paper we make a number of contributions to the literature on the time series properties of real exchange rates. First, we propose a simple equilibrium exchange rate model as initially discussed in Dutta and Leon (2002) which allows for deviations from PPP and is consistent with the risk-adjusted real interest parity relationship, as suggested by Clark and MacDonald (1998). The proposed model captures the long-run exchange rate equilibrium and the short run dynamic adjustment to equilibrium. In contrast to other research on real exchange rates which exploits the real interest parity relationship, we use a univariate modeling framework. ${ }^{1}$

Second, our estimation is conducted in a non-linear framework and we make an econometric contribution by proposing a novel transition function, and we use simulations to show that our empirical transition function matches the exchange rate behaviour suggested by our exchange rate model. Based on our transition function, we propose two structural break tests and report their size and power. Finally, some empirical applications to different real exchange rate data are provided.

The remainder of the paper is organized as follows. In the next section we overview existing work on the univariate properties of real exchange rate determination and also present a simple equilibrium exchange rate model to motivate our econometric analysis. The empirical specification and simulation results are presented in sections 3 and 4, respectively. The results of our empirical tests are contained in section 5 . Finally, section 6 contains a conclusion.

\section{Literature overviews and theoretical modeling}

\subsection{Unit root based analysis}

Unit root tests have been the most common method of investigating the PPP hypothesis. The most popular test of the PPP hypothesis utilises the univariate ADF test, which regresses the real exchange rate on a constant, its lagged level and $p$ lagged first

\footnotetext{
${ }^{1}$ In this paper the idea is to develop unit root tests for structural breaks, which are consistent with the exchange rate behaviour suggested by the economic model.
} 
differences,

$$
q_{t}=\alpha+\beta q_{t-1}+\sum_{i=1}^{p} \phi_{i} \Delta q_{t-i}+\varepsilon_{t}
$$

where $q_{t}$ denotes the real exchange rate and $\alpha$ and $\beta$ are assumed to be constant. ${ }^{2}$ Indeed, previous studies, by using demeaned values of $q_{t}$, under the assumption of constant $\alpha$, do not consider possible effects from economic fundamentals which can potentially be captured by shifts in the mean process of the series. Recent empirical studies indicate that structural change produces slower mean reversion of the real exchange rate.

An important strand in the literature on PPP are the papers which use panel data methods to test the hypothesis. For example, Abauf and Jurion (1990) and Jorion and Sweeney (1996), use monthly data, and conduct panel unit root tests on real exchange rates for the G10 countries and produce evidence of rejection of the unit root null at the $10 \%$ level. In particular, Jorion and Sweeney (1996) employs six more years of monthly data from 1973 to 1993 for 10 currencies against the US dollar and rejects the unit root hypothesis at the $5 \%$ significance level, using no lags of the differenced dependent variable in the ADF regression. For seven European currencies against the Deutschmark, the rejection of a unit root is even stronger, with a $p$-value of 0.002 .

Wu (1996) tests annual, quarterly and monthly dollar real exchange rates for a panel of 18 countries from January 1974 to April 1993 and strongly rejects the unit root hypothesis for both CPI (consumer price index) and WPI (wholesale price index) based rates. In particular, he is able to reject the null at the $1 \%$ level in both cases, and estimates an autoregressive parameter of 0.98 for monthly data. However, since Wu (1996) allows for a time trend, which has as the alternative hypothesis trend stationary rather than levels stationarity, it is hard to say that the rejection of the unit root null provides evidence in favour of PPP.

Oh (1996) employs annual real exchange rate data, constructed from the Summers and Heston data set, for the post Bretton Woods period, and shows a rejection of the unit root hypothesis. This result is much stronger than Frankel and Rose (1996) result obtained with annual data or previous studies with quarterly or monthly data. MacDonald (1996) uses the Levin and Lin panel unit root test and annual data for the post Bretton Woods period and is able to reject a unit root in the real exchange rate at the $5 \%$ significance level

Papell (1997) criticizes regression-based studies on pooled real exchange rates for the free floating periods and suggests considering a heterogenous intercept in the regression, which is equivalent to including country-specific dummy variables. He shows evidence in favor of PPP and a faster rate of mean reversion when the Deutschmark rather than the US dollar is used as a base currency. In particular, the estimated half-life is 2 years in the former case and 2.5 years in the latter. Finally, his empirical results show that PPP is more likely to hold in the case of larger than smaller panels, for monthly rather than quarterly data and when the German mark rather than the US

\footnotetext{
${ }^{2}$ Generally, a time trend is not included in the equation (1) because such an inclusion would be theoretically inconsistent with long-run PPP.
} 
dollar is used as the base currency. However, O'Connell (1998) points out that the empirical evidence favouring PPP is mainly due to tests being badly over-sized when the unit root null is true and provides convincing Monte Carlo evidence to support this assertion. Specifically, employing a pooled GLS-ADF test, which has the correct size in the presence of cross-sectional dependence, he finds no evidence in favour of PPP using a panel of 63 real exchange rates (and smaller regional subpanels), using quarterly data from 1973:2 to 1995:4.

The above empirical evidence on PPP has led researchers to explore alternative methods to attempt to establish the relationship. For example, the large spike in the US dollar in the 1980s led Papell (2002) to suggest incorporating structural change into the estimates. Using panel methods, the test strongly rejects the unit root null for those countries that adhere to the typical pattern of the dollar's rise and fall. Christopher F. Baum and Caglayan (1999) considers fractional integration and mean shifts in a single currency. In their study, they use both CPI- and WPI-based rates and demonstrate that the unit root hypothesis is robust against both fractional alternatives and structural breaks. This evidence suggests rejection of the unit root during the floating period and structural changes. Bleaney and Leybourne (2003) point out that the rejection of the unit root hypothesis is not necessarily correct because these tests strongly over-reject the null in certain circumstances, particularly when the series have a stochastic unit root. Sollis (2005) recently suggests using univariate smooth transition models, which allow, under the alternative hypothesis, for stationarity around a gradually changing deterministic trend function. The test reveals statistically significant evidence against the null hypothesis of a unit root for the real exchange rates of a number of countries against the US dollar. However, the tests include a time trend and the results are rather weak within a conservative PPP framework.

\subsection{Modeling equilibrium exchange rate}

This section introduces a simple model of the real exchange rate. We propose that the exchange rate dynamics for the real exchange rate, $q_{t}$, are determined by the lagged real exchange rate, $q_{t-1}$, a fundamental term $z_{t-1}=r_{t-1}-r_{t-1}^{*}$, which is the difference between home and foreign real interest rates, and $s_{t}$, which we interpret as the stationary part of the real exchange rate and is driven by non-fundamentals, such as the many kind of trading rules described in the technical analysis literature:

$$
q_{t}=\beta q_{t-1}+m z_{t-1}+s_{t}+\varepsilon_{t},
$$

where $0<\beta<1$, and $\varepsilon_{t} \sim$ i.i.d. Taking expectations we have

$$
E_{t-1}\left(q_{t}\right)=\beta q_{t-1}+m z_{t-1},
$$

where $\left.E_{t-1} q_{t}\right|_{s_{t}=0}=\bar{q}_{t} \cdot{ }^{3}$ In this model the parameter $m$ is important and captures the persistence of monetary policy. Thus, a negative value of this parameter would

\footnotetext{
${ }^{3}$ Survey studies find that FX market participants tend to have extrapolative expectations over short-term horizons and mean-reverting over longer horizons.
} 
suggest reversion to the equilibrium. Note that, in this context, if $m=0$, the model is consistent with a traditional interpretation of PPP.

We now introduce the risk adjusted real interest parity condition which can be derived by a manipulatiomn of the the uncovered interest parity (UIP) condition, $q_{t}=q_{t-1}+r_{t-1}^{*}-r_{t-1}$ with rational expectations imposed, as suggested by Clark and MacDonald (1998), ${ }^{4}$

$$
E_{t-1}\left(q_{t}\right)=q_{t-1}+r_{t-1}^{*}-r_{t-1}+\pi_{t-1},
$$

where $\pi_{t-1}$ is a wedge and is normally interpreted as a risk premium although it could equally reflect an expectational error that represents deviations from uncovered interest parity (or indeed both).

From the two orthogonal relationships, (2) and (3), we can obtain an explicit reduced form for $z_{t-1}$ in an equilibrium state

$$
z_{t-1}=\frac{1}{m+1} \pi_{t-1}+\frac{m+\beta}{m+1} q_{t-1} .
$$

In our model, when we further assume that $s_{t}=\lambda\left(\bar{q}_{t}\right)$ we obtain:

$$
s_{t}=\left\{\begin{array}{ccc}
\lambda_{L}\left(q_{L}-\bar{q}_{t}\right) & & \bar{q}_{t}<q_{L} \\
0 & \text { if } & q_{L}<\bar{q}_{t}<q_{H} \\
\lambda_{H}\left(q_{H}-\bar{q}_{t}\right) & & q_{H}<\bar{q}_{t}
\end{array}\right.
$$

where $0 \leq \lambda_{i} \leq 1$ and $i=L, H$. That is, when $s_{t}=0$ (i.e. the inner regime), equation (4) is satisfied. After substituting (4) into (3) we have

$$
q_{t}=\left\{\begin{array}{ccc}
a_{L}+b_{L} q_{t-1} & & \bar{q}_{t}<q_{L} \\
a_{0}+b_{0} q_{t-1} & \text { if } & q_{L}<\bar{q}_{t}<q_{H} \\
a_{H}+b_{H} q_{t-1} & q_{H}<\bar{q}_{t}
\end{array} .\right.
$$

Thus, in the inner regime the real exchange rate is given by $q_{t}=a_{0}+b_{0} q_{t-1}$ and the parameter $a_{0}$, and the other cases for $q_{t}$ outside the inner regime, can be obtained in a similar way and we report the solutions below:

$$
\begin{array}{lll}
a_{L}=\frac{\lambda_{L} q_{L}}{1+m\left(1-\lambda_{L}\right)}+\frac{m\left(1-\lambda_{L}\right)}{1+m\left(1-\lambda_{L}\right)} \pi_{t-1} & b_{L}=\frac{\left(1-\lambda_{L}\right)(m+\beta)}{1+m\left(1-\lambda_{L}\right)} \\
a_{0}=\frac{m}{1+m} \pi_{t-1} & \text { and } & b_{0}=\frac{(m+\beta)}{1+m} \\
a_{H}=\frac{\lambda_{H} q_{H}}{1+m\left(1-\lambda_{H}\right)}+\frac{m\left(1-\lambda_{H}\right)}{1+m\left(1-\lambda_{H}\right)} \pi_{t-1} & b_{H}=\frac{\left(1-\lambda_{H}\right)(m+\beta)}{1+m\left(1-\lambda_{H}\right)}
\end{array}
$$

In the present setting, when the expected value, $\bar{q}_{t}$ is $q_{L}<\bar{q}_{t}<q_{H}, s_{t}=0$, the exchange rate is at its equilibrium level and $\lambda=0$. On the other hand, when $\bar{q}_{t}$ falls below $q_{L}$ or rises above $q_{H}$, market participants will trade according to the following strategy: $s_{t}=\lambda_{L}\left(q_{L}-\bar{q}_{t}\right)$ and $s_{t}=\lambda_{H}\left(q_{H}-\bar{q}_{t}\right)$.

A similar approach can be used to determine the exchange rate dynamics when the exchange rate drifts away from its long-run equilibrium value. In this case, the stationary part of the exchange rate will play an ${ }_{5}$ portant role. The structural parameters 


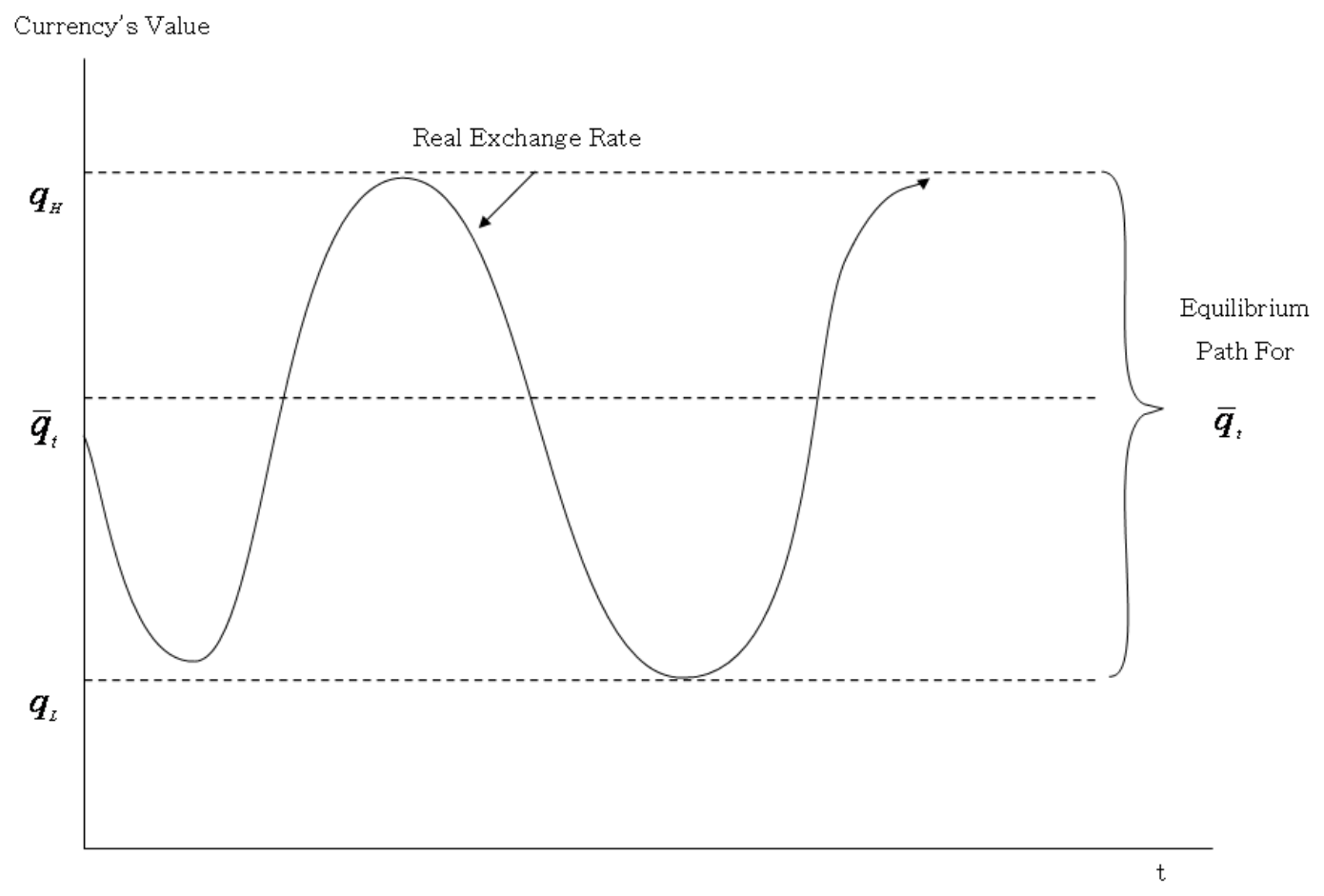

Figure 1: Equilibrium Exchange Rate Path

$(m, \beta)$ are not identified but equation (5) provides a testable implication where the stationarity of $q_{t}$ depends on the sign of parameter $b_{0}$.

In contrast to Dutta and Leon $(2002)^{5}$ the intercept $a_{0}$ in our model varies around the equilibrium path $\left[q_{L}, q_{H}\right]$. The shift of the intercept in this range allows us to capture monetary policy activities and/or balance sheet adjustments amongst dealers in the market ${ }^{6}$. We assume that when the exchange rate fluctuates within this bound,

\footnotetext{
${ }^{4}$ Dutta and Leon (2002) employ uncovered interest parity condition, $E_{t-1}\left(q_{t}\right)=q_{t-1}+r_{t-1}^{*}-r_{t-1}$

${ }^{5}$ The coefficients $a_{i}$ and $b_{i}$ in Dutta and Leon (2002) model are derived as

$$
a_{L}=\frac{\lambda_{L} q_{L}}{1+m\left(1-\lambda_{L}\right)} \quad b_{L}=\frac{\left(1-\lambda_{L}\right)(m+\beta)}{1+m\left(1-\lambda_{L}\right)}
$$$$
\begin{aligned}
a_{0}=0 & \text { and } & b_{0}=\frac{(m+\beta)}{1+\beta} \\
a_{H}=\frac{\lambda_{H} q_{H}}{1+m\left(1-\lambda_{H}\right)} & & b_{H}=\frac{\left(1-\lambda_{H}\right)(m+\beta)}{1+m\left(1-\lambda_{H}\right)}
\end{aligned}
$$

Thus, the intercept is zero around the equilibrium path $\left[q_{L}, q_{H}\right]$, where the uncovered interest parity

${ }^{6}$ When the exchange rate fluctuates within this range there is not trading activities since trading a currency would not be justified by its trandaction costs. However, there might be "hot potato" trading,
} holds. 
the risk premium is very small but yet $\pi>0$. The inclusion of a non-zero intercept in this case has some noticeable advantages. If for simplicity we assume a constant $\pi_{t-1}$, when monetary policy is effective $|m|<1$, the equilibrium exchange rate $\bar{q}_{t}$ moves upward when $0<m<1$, and downward when $-1<m<\dot{0}$.

Figure (1) shows the theoretical issues mentioned above and how the equilibrium path is determined. Thus, our model allows for structural shifts around a long-run equilibrium mean, induced by changes in the wedge, $\pi$, which as we have said either reflects risk factors or expactational error and/or the monetary effect, $m$. In the next sections we propose unit root tests for structural change, where the transition function considered is able to replicate the exchange rate dynamics arising from the model introduced above ${ }^{7}$.

\section{Model specification}

\subsection{Overviews on unit root test with structural change}

Unit root tests have been widely criticized because the incorrect specification of the intercept can have signifcant implications for the test results. For example, Perron (1989) argues that if the deterministic intercept and/or trend have structural change, the tests will produce a misleading conclusion that there is a unit root, when in fact there is not. In this section we present a selective survey of unit roots tests in the presence of structural breaks.

\subsubsection{Tests assuming a known break}

The earliest test for structural change in the economic literature was suggested by Chow (1960). This test considers stationary variables and a single break only. Perron (1989) proposes a modified Dickey-Fuller (hereafter DF) test for a unit root with three different types of deterministic trend functions, given a known structural break which is assumed to be determined exogenously. Perron (1989) presents Monte Carlo results with a trend-stationary process and shows the effect that a shift in the level of the series, or a shift in the slope, would have on the standard unit root test. Perron (1989) finds that tests of a unit root are not consistent against trend-stationary alternatives when the trend function contains a shift in the slope or a shift in the intercept. In these cases the power of unit root tests is substantially reduced.

On the basis of these results, Perron (1989) develops a testing procedure involving ADF regressions, modified with dummy variables to ensure consistent tests for stationarity in the presence of structural breaks at time $1<T_{B}<T$. He considers the

and/or monetary policy, which will make the exchnage rate fluctuate around its long-run equilibrium value.

${ }^{7}$ Another argument in favour of our approach is in Lyons (1999). Indeed this paper points out that portfolio shifts in the the foreign exchange market are likely to be gradual rather than abrupt. 
following three models,

$$
\begin{aligned}
& \text { Model (I): } D T_{t}=a_{0}+a_{1} D U_{t}+b_{t} \text { where } D U_{t}=\left\{\begin{array}{l}
1 \\
0
\end{array} \text { if } \begin{array}{l}
t>T_{B} \\
t \leq T_{B}
\end{array}\right. \\
& \text { Model (II): } D T_{t}=a+b_{0} t+b_{1} D T_{t} \text { where } D T_{t}=\left\{\begin{array}{l}
t-T_{B} \quad \text { if } \begin{array}{l}
t>T_{B} \\
0
\end{array} \\
\begin{array}{l}
t \leq T_{B}
\end{array}
\end{array}\right. \\
& \text { Model (III): } D T_{t}=a_{0}+a_{1} D U_{t}+b_{0} t+b_{1} D T_{t} \text { where } D T_{t}=\left\{\begin{array}{ll}
t \\
0
\end{array} \begin{array}{l}
t>T_{B} \\
t \leq T_{B}
\end{array}\right.
\end{aligned}
$$

where Model (I) permits an exogenous change in the level of the series, Model (II) allows an exogenous change in the rate of growth, and Model (III) admits both changes.

Perron (1989) applies the tests to the U.S. data set first examined by Nelson and Plosser (1982) and consisting of annual observations on fourteen indices of various economic time series. The results contradicted the original finding of Nelson and Plosser (1982) that thirteen out of the fourteen series could be characterized as $I(1)$ processes. Perron's results suggested that rather than being $I(1)$, many macroeconomic time series were in fact stationary around a deterministic trend with a structural break.

\subsubsection{Tests assuming an unknown break}

The model suggested by Perron (1989) has been criticized on the grounds that it assumes the break point to be known. Zivot and Andrews (1992) argue that if the break is treated as endogenous, then Perron's conclusions are reversed. Zivot and Andrews (1992) argue that, while Perron (1989) assumes events such as the 1929 Great Depression and 1973 oil crisis to be exogenous, the effects of such events could be interpreted as a realization from the tail of the underlying data generating process. Furthermore, if structural change is caused by an event endogenous to the domestic economy such as financial deregulation, then the correct unit root test procedure should account for the fact that the break points in the regressions might be data dependent. Zivot and Andrews (1992) develop a unit root test where the time of the structural break, under the alternative hypothesis, is indeed determined by the data.

Zivot and Andrews (1992) are concerned with the estimation of the break point that gives most weight to the trend stationary alternative hypothesis. Hence, the time of the break is selected by sequentially modelling a structural break in ADF regressions, and then choosing the break for which the DF $t$-statistic is minimized. For all of the models, Zivot and Andrews (1992) derive the asymptotic null distribution of their test statistics and tabulate asymptotic null critical values.

Zivot and Andrews (1992) apply their tests to the same Nelson and Plosser data series but the overall results are weaker than the ones obtained in Perron (1989).

\subsubsection{Tests based on smooth transition functions}

Leybourne et al. (1998) argue that while the Zivot-Andrews test offers an improvement over the Perron's test by endogenising the structural break, it is still limited since it 


\begin{tabular}{l|l|l}
\hline \hline \multicolumn{1}{c|}{ Model } & \multicolumn{1}{|c|}{ Transition Function: $S_{t}(\theta)$} & Parameter: $\theta$ \\
\hline LSTR & {$[1+\exp \{-\gamma(t-c T)\}]^{-1}$} & $\gamma, c$ \\
ESTR & $1-\exp \left[-\gamma^{2}(t-c T)^{2}\right]$ & $\gamma, c$ \\
Asymmetric ESTR & $1-\exp \left[-I_{t} \gamma_{1}^{2}(t-c T)^{2}-\left(1-I_{t}\right) \gamma_{2}^{2}(t-c T)^{2}\right]$ & $\gamma_{1}, \gamma_{2}, c$ \\
\hline \hline
\end{tabular}

Table 1: Functions for Structural Change

can be misspecified when the structural break is gradual rather than instantaneous. With economic time series generally dependent on the behavior of individual agents with different amounts of information and ability, gradual adjustment from one regime to another seems a more attractive proposition than the instantaneous break imposed in the Zivot-Andrews procedure. Thus, a smooth transition function is considered in order to account for stationarity around an endogenously determined intercept and/or trend. Leybourne et al. (1998) suggest the following three regression models,

$$
\begin{array}{ll}
\text { Model (A): } & y_{t}=a_{0}+a_{1} S_{t}(\theta)+u_{t} \\
\text { Model (B): } & y_{t}=a_{0}+a_{1} S_{t}(\theta)+b_{0} t+u_{t} \\
\text { Model (C): } & y_{t}=a_{0}+a_{1} S_{t}(\theta)+b_{0} t+b_{1} t S_{t}(\theta)+u_{t}
\end{array}
$$

where $u_{t}$ is a zero-mean $I(0)$ process and $S(\theta)$ is a smooth transition function based on sample of size $T$ and the parameter set $\theta$.

The transition functions $S_{t}(\theta)$ considered in previous studies are given in Table (1). These are all variations of the modified exponential transition. Nelder (1971)

$$
S_{t}(\theta)=\frac{1}{\left[1+\exp \left\{-\frac{\gamma(t-c T)}{\delta}\right\}\right]^{\delta}},
$$

where $\delta=1$ is consistent with the logistic function. The function traverses the interval $(0,1)$, where $t=c T$ is the inflexion point of the function.

The structural change with logistic smooth transition (hereafter LSTR) is the one considered in Leybourne et al. (1998). The function is bounded between 0 and 1, and the time of the transition is determined by $c$. For $\gamma>0$, we have that $S_{-\infty}(\theta)=0$, $S_{+\infty}(\theta)=1$ and $S_{c T}(\theta)=0.5$. This corresponds to the point of inflexion of the logistic function occurring when $t=c T$. The speed of the transition is determined by the parameter $\gamma$.

Since the logistic function-based models are unable to capture more than one break, Sollis (2005) extends the model by considering an exponential smooth transition (hereafter ESTR) and asymmetric exponential smooth transition (hereafter Asymmetric ESTR). This function traverses the interval $(0,1)$ as $(t-c T) \rightarrow \pm \infty$, and is symmetric or asymmetric around the time of the transition $c T$. The value of $S_{t}(\theta)$ depends on the value of the parameter $\gamma$ and when $t=c T$, transition function $S\left(y_{t-d}, \theta\right)$ takes converges to zero.

To illustrate the nature of the transition functions mentioned above, Figure (2) graphically compares their characteristics. The LSTR function only considers a single 


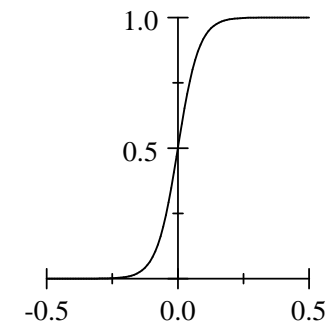

LSTR

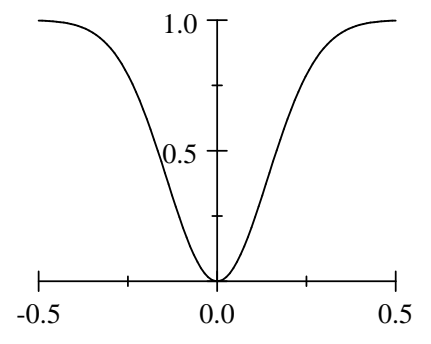

ESTR

Figure 2: Simulation for the LSTR and ESTR

break whereas the ESTR function considers multiple breaks. In Figure (2) we plot the function considering $\gamma=5$. Thus, with the ESTR function, the structural change is an inner regime.

The asymmetric ESTR suggested by Sollis et al. (2002) has similar properties as the ESTR but it allows asymmetric scale parameters, $\gamma_{1}$ and $\gamma_{2}$ where $I_{t}=1$ if $(t-c T) \leq 0$ and 0 otherwise. The transition function $S_{t}(\theta)$ is also bounded from 0 to 1 when the $\gamma_{1}$ and $\gamma_{2}$ are sufficiently large values and if $\gamma_{1} \neq \gamma_{2}$ the speed of transition is asymmetric either side of the mid-point $c T$.

\subsection{The econometric model}

Thus, the functions used by Leybourne et al. (1998) and by Sollis (2005) to estimate deviation from equilibrium are the logistic and the exponential functions, respectively. In this section we shall propose a more flexible transition function which considers multiple structural changes and allows fits our exchange rate model proposed in the previous section.

\subsubsection{The symmetric smooth transition}

We consider the following transition function

$$
\left[1+\exp \left\{-\gamma^{2}\left(t-c_{1} T\right)^{2}\right\}\right]\left[1-\exp \left\{-\gamma^{2}\left(t-c_{2} T\right)^{2}\right\}\right]-1 .
$$

This modification allows for symmetric movement from zero and inflexion point of the function defined by structural changes along a given equilibrium path.

The function (7) is plotted graphically in Figure (3). The function is plotted for the same positive and negative values with the same scale parameter $\gamma$. As shown in the left-hand-side panel of Figure (3), $1+\exp \left\{-\gamma_{1}^{2}\left(t-c_{1} T\right)^{2}\right\}$ moves between 0 and 2 , and $1-\exp \left\{-\gamma_{1}^{2}\left(t-c_{2} T\right)^{2}\right\}$ between 0 and 1. Thus, our transition function ranges between 0 and 2. In our empirical applications we have normalized the function between -1 and 1 . 

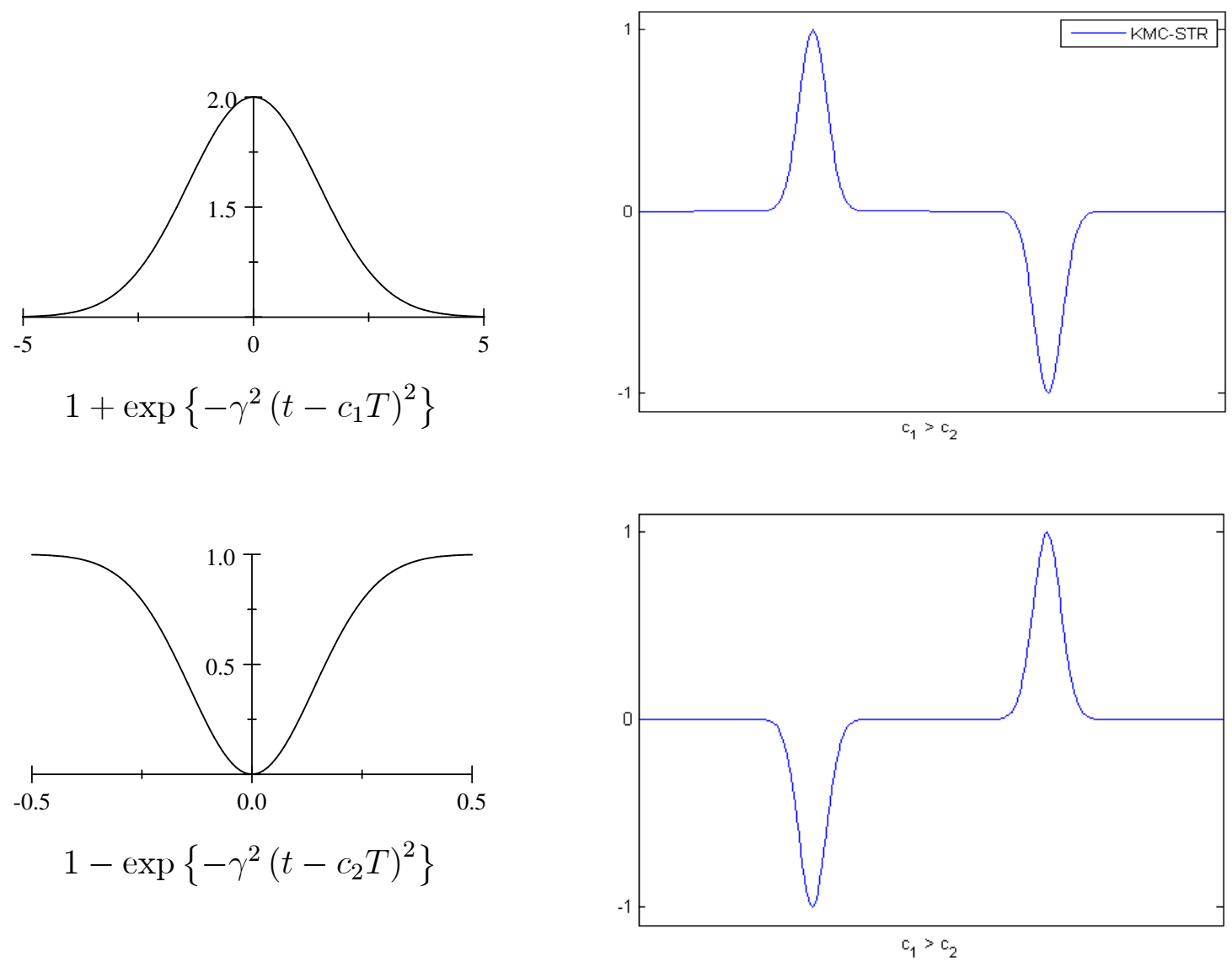

Figure 3: Simulation for KMC-STR

The speed at which the function moves between -1 and 1 changes with $\gamma$. As shown in Figure (3), this (empirical) model matches very closely the exchange rate dynamics arising from the model proposed in the previous section and it is therefore able to capture structural changes taking place in the overvaluation regime as well as in the undervaluation regime. If $c_{1}<c_{2}, 0<S_{t}(\theta)<1$ when $t=c_{1} T$, and $-1<S_{t}(\theta)<0$ when $t=c_{2} T$. In the limiting state $S_{t}(\theta)=0$ the Model (A) collapses to $y_{t}=a_{0}+u_{t}$, and $a_{0}$ is consistent with the (economic) model proposed above.

Thus, in contrast to the existing smooth transition functions, LSTR and ESTR, our proposed function $K M C-S T R$ is able to capture the adjustment process along the equilibrium path due to a risk premium, $\pi_{t-1}$, in the equilibrium exchange rate model, plus the non fundamental influences reflected in $s$.

We now consider an extension of the symmetric specification presented above to incorporate asymmetry. Consider, for example, the different scale parameter, $\gamma_{1}^{2}$ and $\gamma_{2}^{2}$. In this case the transition function above can be re-written as:

$$
\begin{gathered}
{\left[1+\exp \left\{-\gamma_{1}^{2}\left(t-c_{1} T\right)^{2}\right\}\right]\left[1-\exp \left\{-\gamma_{2}^{2}\left(t-c_{2} T\right)^{2}\right\}\right]-1} \\
11
\end{gathered}
$$



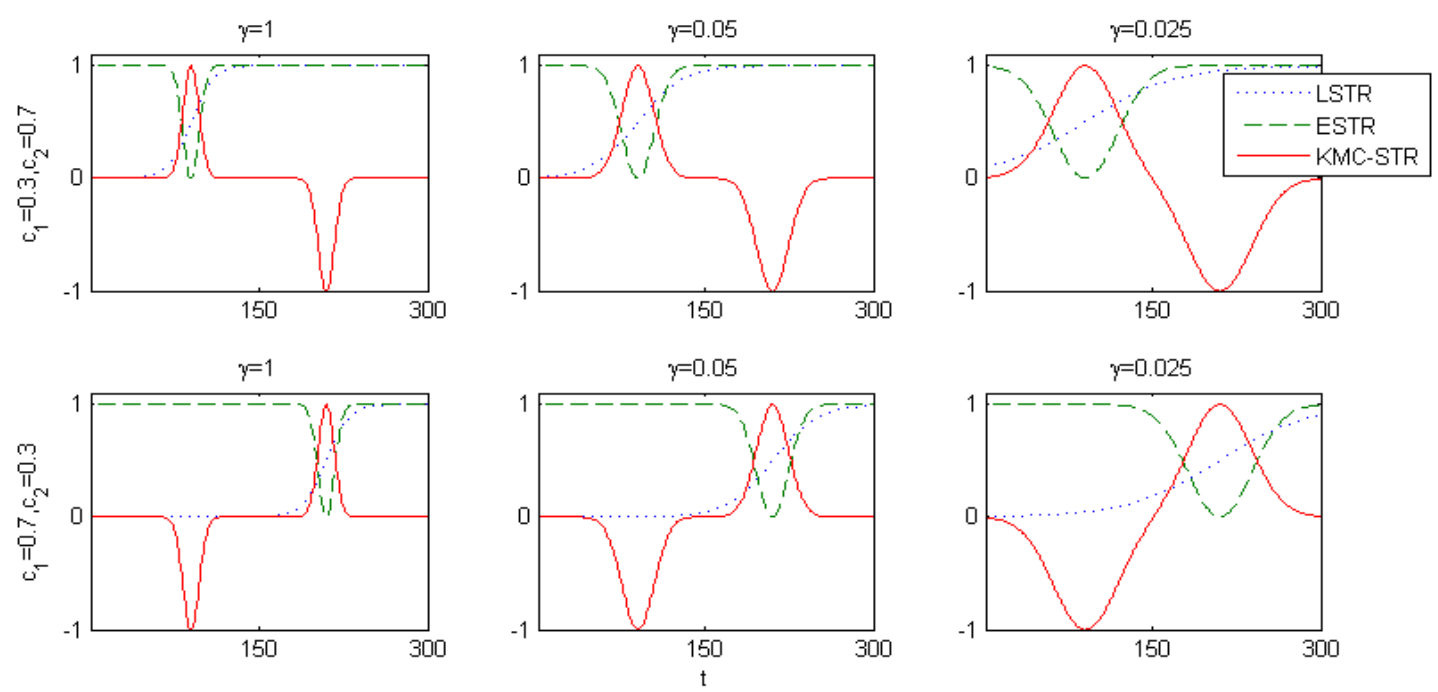

Figure 4: Properties of LSTR, ESTR, and KMC-STR

The fundamental properties of the transition function (8) are the same as in the symmetric case. However, since $\gamma_{1}^{2} \neq \gamma_{2}^{2}$, the function $S_{t}(\theta)$ is asymmetric around zero from its limiting values, 1 or -1 .

\subsubsection{Simulation Results}

To show the advantages of our transition function with respect to others recently proposed in the literature, we perform simulations and compare the proposed model with representative transition functions, LSTR and ESTR, in a sequence of $t \in[1,300]$, $c_{i}=0.3$ and 0.7 and, for simplicity, symmetric scale parameter, $\gamma=\{1,05,0.025\}$ respectively.

The Figure (4) shows the nature of the transition function. As pointed out above, our proposed model is more flexible than other existing ones. For example, the LSTR is only able to capture the transition from $I(0)$ to $I(1)$ process - thereby it only considers one structural change. The ESTR, by considering multiple changes, provides an improvement over the LSTR. However, with these two models (i.e. LSTR and ESTR) the change is restricted to take place in a certain region, for example above zero and reversal to the equilibrium. When the break takes place around the equilibrium, the previous models are rather restrictive. It is clear that the proposed $K M C-S T R$ function (4) can flexibly capture structural changes around the equilibrium path and the exchange rate dynamics, in this case, are consistent with the exchange rate behaviour in section 2.2 . 


\subsection{Estimation method}

At this point the objective is to develop unit root tests for structural breaks based on the transition function introduced in the previous section. The models (A-C) considered below have different types of structural changes. Assuming that $u_{t}$ is an $I(0)$ process then in Model (A) $y_{t}$ is stationary around a mean which changes from the initial value $a_{0}$ to final value $a_{0}+a_{1}$. In Model (B) the intercept changes from $a_{0}$ to $a_{0}+a_{1}$, but the model contains a fixed slope term. Finally, in Model (C) both the intercept and the slope change simultaneously, from $a_{0}$ to $a_{0}+a_{1}$ and $b_{0}$ to $b_{0}+b_{1}$, respectively.

Thus under Models A-C we have

$$
\begin{array}{ll}
H_{0}: & y_{t}=u_{t}, u_{t}=u_{t-1}+\varepsilon_{t}, u_{0}=\psi \\
H_{1}: & \text { Model (A), Model (B), Model (C) }
\end{array}
$$

and

$$
\begin{array}{ll}
H_{0}: & y_{t}=u_{t}, u_{t}=\kappa+u_{t-1}+\varepsilon_{t}, u_{0}=\psi \\
H_{1}: & \text { Model (B), Model (C) }
\end{array}
$$

where $\varepsilon_{t}$ is assumed to be a stationary process with zero mean.

The test statistics can be computed using a two-step procedure. Firstly, we estimate the deterministic component of the model using a nonlinear least square (hereafter NLS) algorithm and compute the residuals

$$
\begin{array}{ll}
\text { Model (A): } & \hat{u}_{t}=y_{t}-\hat{a}_{0}-\hat{a}_{1} S_{t}(\hat{\theta}) \\
\text { Model (B): } & \hat{u}_{t}=y_{t}-\hat{a}_{0}-\hat{a}_{1} S_{t}(\hat{\theta})-\hat{b}_{0} t \\
\text { Model (C): } & \hat{u}_{t}=y_{t}-\hat{a}_{0}-\hat{a}_{1} S_{t}(\hat{\theta})-\hat{b}_{0} t-\hat{b}_{1} t S_{t}(\hat{\theta})
\end{array}
$$

The model parameters to be estimated are $\hat{a}, \hat{b}$ and the parameter set, $\theta$, of the transition function. The parameter set of interest suffers from unidentified parameter problem introduced by Davies (1987). For the models A-C, Leybourne et al. (1998) suggests a way of simplifying the nonlinear computation problem. That is, they note that the NLS can be concentrated with respect the estimates, $\hat{a}$ and $\hat{b}$ when the fixed values of the parameter set in transition function are given. Taking Model (C) as an example, the estimated parameters of Model (C) can be obtained by OLS

$$
\hat{\theta}=\arg \min _{\theta} \sum_{t=1}^{T}\left(y_{t}-\hat{\beta}(\theta)^{\prime} x_{t}(\theta)\right)^{2}=\arg \min _{\theta} \hat{\sigma}^{2}(\theta),
$$

where $x_{t}(\theta)=\left[1, t, S_{t}(\hat{\theta}), S_{t}(\hat{\theta}) t\right]$ and $\hat{\beta}(\theta)=\left(\sum_{t=1}^{T} x_{t}(\theta) x_{t}(\theta)^{\prime}\right)^{-1}\left(\sum_{t=1}^{T} x_{t}(\theta) y_{t}\right)$.

To circumvent an initial value problem, we first determine sensible initial values, which are obtained using a grid search over $c_{i}$ and $\gamma_{i}$. A meaningful set of values for the parameters, $c_{i}$, are defined as sample percentiles as suggested by Caner and Hansen (2001). We therefore set $c_{i}$ as

$$
\left[Q(15){ }_{13} Q(85)\right]
$$


where $Q(15)$ and $Q(85)$ are the 15 th and 85th percentiles of $T$.

At the same time, to determine a useful set of scale parameter $\gamma_{i}$, Dijk et al. (2002) suggests rescaling the transition function with the sample standard deviation, which makes $\gamma_{i}$ approximately scale-free. The transition parameters were then standardized through division by its sample variance. We estimate the scale parameter $\gamma_{i}$ over the interval given by

$$
\left[10^{-1} P_{n}, 10^{3} P_{n}\right]
$$

where $P_{n}=\left(\sum_{t=1}^{n} \frac{y_{t}^{2}}{n}\right)^{-\frac{1}{2}}$.

At each step in the grids, the parameter set $\theta$ was estimated so as to minimize the residual sum of squares. When the combination of parameters $c_{i}$ and $\gamma_{i}$ provided the overall minimum of the residual sum of squares, NLS estimation was used using the Broyden, Fletcher, Goldfarb and Shanno (BFGS) optimization algorithm in MATLAB 2008.

We then compute the $\mathrm{ADF} t$-statistic associated with $\rho$ in the ordinary least squares (OLS) regression

$$
\Delta \hat{u}_{t}=\rho \hat{u}_{t-1}+\sum_{i=1}^{k} \phi_{i} \Delta \hat{u}_{t-i}+\hat{\varepsilon}_{t}
$$

where the lagged difference terms are included to account for residual autocorrelation. The statistics associated with models $\mathrm{A}, \mathrm{B}$, and $\mathrm{C}$ are denoted $t^{A}, t^{B}$ and $t^{C}$, respectively.

\section{Monte Carlo experiment}

\subsection{Critical value}

With NLS estimation closed-form solutions are generally difficult to obtain therefore Leybourne et al. (1998), for example, estimates the null distribution of the test using Monte Carlo simulation. The critical values of the test statistics associated with models A, B, and C can be computed using the same two-step procedures as in Leybourne et al. (1998) and Sollis (2005), but replacing the transition function with the $K M C-S T R$. The null DGP was specified as a random walk with standard normal error terms,

$$
\begin{aligned}
y_{t} & =u_{t} \\
u_{t} & =u_{t-1}+\varepsilon_{t} \varepsilon_{t} \sim N I D(0,1) \\
u_{0} & =\psi
\end{aligned}
$$

and $\psi=0$. We set $k$ equal to zero. The null distribution of the test was estimated using Monte Carlo simulation and based on 10,000 replications. For the symmetric and asymmetric $K M C-S T R$ tests, the critical values of the null distributions of the tests at $1 \%, 5 \%$ and $10 \%$ significance levels are given in Table (2). As expected given the extra parameters being estimated, the critical values for this test are bigger in absolute value than the ones for the DF-GLS tests. 14 


\begin{tabular}{|c|c|c|c|c|c|c|c|c|c|}
\hline \multicolumn{10}{|c|}{ Null Critical Values } \\
\hline \multirow[t]{2}{*}{$T$} & \multicolumn{3}{|c|}{$t_{S}^{A}$} & \multicolumn{3}{|c|}{$t_{S}^{B}$} & \multicolumn{3}{|c|}{$t_{S}^{C}$} \\
\hline & $1 \%$ & $5 \%$ & $10 \%$ & $1 \%$ & $5 \%$ & $10 \%$ & $1 \%$ & $5 \%$ & $10 \%$ \\
\hline 100 & -4.581 & -3.951 & -3.626 & -4.984 & -4.330 & -4.004 & -5.183 & -4.563 & -4.248 \\
\hline 200 & -4.450 & -3.885 & -3.574 & -4.783 & -4.226 & -3.940 & -5.000 & -4.453 & -4.143 \\
\hline 300 & -4.412 & -3.854 & -3.564 & -4.760 & -4.210 & -3.920 & -4.958 & -4.432 & -4.140 \\
\hline \multirow[t]{2}{*}{1000} & -4.403 & -3.839 & -3.543 & -4.758 & -4.203 & -3.915 & -4.938 & -4.413 & -4.139 \\
\hline & \multicolumn{3}{|c|}{$t_{A S}^{A}$} & \multicolumn{3}{|c|}{$t_{A S}^{B}$} & \multicolumn{3}{|c|}{$t_{A S}^{C}$} \\
\hline 100 & -5.005 & -4.388 & -4.058 & -5.177 & -4.571 & -4.258 & -5.559 & -4.973 & -4.662 \\
\hline 200 & -4.887 & -4.281 & -3.973 & -5.060 & -4.485 & -4.172 & -5.459 & -4.852 & -4.555 \\
\hline 300 & -4.824 & -4.272 & -3.971 & -5.015 & -4.476 & -4.162 & -5.335 & -4.802 & -4.519 \\
\hline 1000 & -4.808 & -4.224 & -3.924 & -4.987 & -4.457 & -4.160 & -5.329 & -4.762 & -4.496 \\
\hline
\end{tabular}

Table 2: Critical Values for Symmetric and Asymmetric KMC-STR

\subsection{The size of the test}

In this section, we perform a Monte Carlo investigation of the test above and compare it with the Dickey-Fuller test, using the $5 \%$ asymptotic critical values provided in table (2). All results have empirical rejection frequencies from 1,000 replications when the underlying DGP is the random walk process.

In these experiments, we follow Leybourne et al. (1998) and Sollis (2005) and use the following $\operatorname{ARIMA}(1,1,0)$,

$$
\begin{aligned}
y_{t} & =u_{t} \\
\Delta u_{t} & =\phi \Delta u_{t-1}+\varepsilon_{t}, \varepsilon_{t} \sim N I D(0,1)
\end{aligned}
$$

where $\varepsilon_{t}$ follows the standard normal distribution.

We consider how the size is affected by the parameter $\phi, k$ and consider the sample sizes 100,200 , and 300 where $\phi=\{-0.4,0,0.4\}$ and $k=\{0,1,4\}$, respectively. Table (3) reports the actual rejection rate of the symmetric and asymmetric $K M C-S T R$ tests, $t_{S}^{A}$ and $t_{A S}^{A}$, and compares them with those of the standard Dickey-Fuller test $t_{D F}$. The tests are close to the nominal level of $5 \%$ with good acceptable size in the absence of serially correlated errors, even when the number of observations is small. When the error is serially correlated, however, the size distortion could become a problem. In this case, it seems desirable to make the finite sample adjustments based on the fitted AR models and use the size corrected critical values based on the fitted AR model. 


\begin{tabular}{|c|c|c|c|c|c|c|c|c|c|}
\hline & \multicolumn{3}{|c|}{$\phi=-0.4$} & \multicolumn{3}{|c|}{0} & \multicolumn{3}{|c|}{0.4} \\
\hline & $t_{S}^{A}$ & $t_{A S}^{A}$ & $t_{D F}$ & $t_{S}^{A}$ & $t_{A S}^{A}$ & $t_{D F}$ & $t_{S}^{A}$ & $t_{A S}^{A}$ & $t_{D F}$ \\
\hline \multicolumn{10}{|l|}{$k=0$} \\
\hline$T=100$ & 0.415 & 0.639 & 0.000 & 0.054 & 0.060 & 0.042 & 0.005 & 0.004 & 0.032 \\
\hline 200 & 0.406 & 0.579 & 0.000 & 0.054 & 0.053 & 0.061 & 0.003 & 0.003 & 0.030 \\
\hline 300 & 0.386 & 0.516 & 0.000 & 0.050 & 0.050 & 0.064 & 0.001 & 0.003 & 0.033 \\
\hline \multicolumn{10}{|l|}{$k=1$} \\
\hline$T=100$ & 0.052 & 0.074 & 0.004 & 0.042 & 0.069 & 0.004 & 0.053 & 0.058 & 0.004 \\
\hline 200 & 0.043 & 0.050 & 0.004 & 0.029 & 0.053 & 0.003 & 0.041 & 0.074 & 0.004 \\
\hline 300 & 0.038 & 0.067 & 0.004 & 0.031 & 0.060 & 0.004 & 0.028 & 0.054 & 0.002 \\
\hline \multicolumn{10}{|l|}{$k=4$} \\
\hline$T=100$ & 0.018 & 0.052 & 0.004 & 0.028 & 0.050 & 0.005 & 0.033 & 0.056 & 0.010 \\
\hline 200 & 0.034 & 0.033 & 0.005 & 0.042 & 0.045 & 0.002 & 0.018 & 0.035 & 0.005 \\
\hline 300 & 0.032 & 0.048 & 0.005 & 0.028 & 0.038 & 0.004 & 0.023 & 0.040 & 0.001 \\
\hline
\end{tabular}

Table 3: Size of Symmetric and Asymmetric KMC-STR

\subsection{The power of the test}

In this section we assess the power of the $K M C-S T R$ tests. We employ the following DGP,

$$
\begin{aligned}
y_{t}= & \left\{\begin{array}{l}
a_{0}+a_{1} S_{t}(\theta)+u_{t} \\
a_{0}+a_{1} S_{t}(\theta)+b_{0} t+u_{t} \\
a_{0}+a_{1} S_{t}(\theta)+b_{0} t+b_{1} t S_{t}(\theta)+u_{t}
\end{array}\right. \\
S_{t}(\theta)= & {\left[1+\exp \left\{-\gamma_{1}^{2}\left(t-c_{1} T\right)^{2}\right\}\right]\left[1-\exp \left\{-\gamma_{2}^{2}\left(t-c_{2} T\right)^{2}\right\}\right]-1 } \\
u_{t}= & \phi u_{t-1}+\varepsilon_{t}, \varepsilon_{t} \sim N I D(0,1)
\end{aligned}
$$

A similar DGP was also used in Leybourne et al. (1998). The impact of different transition speeds and inflexion points are considered for a sample size $T=\{100,200\}$. We consider series with $\phi=0.8$ and allow for slow transitions $(\gamma=0.01)$, medium speed transition $(\gamma=0.1)$ and fast transition $(\gamma=1)$.

Leybourne et al. (1998) compares the power of the tests with an $t_{D F}$ for a stationary $A R(1)$ generating process, finding it to be unbiased and consistent. We do not report the power results for the $t_{D F}$ test here. However, as expected, the power of symmetric and asymmetric $K M C-S T R$ tests are very close to the $t_{D F}$ due to the fact that the symmetric and asymmetric $K M C-S T R$ requires the estimation of more parameters than the $t_{D F}$. Sollis (2005) compares the model with other structural break models suggested by Papell (2002) and argues that the instantaneous-break test can suffer from a significant loss in power when trend-breaks are gradual. Our investigation therefore involves comparing the power of the asymmetric $K M C-S T R$ test with the ESTR $\left(e_{a}\right)$ for a stationary generating process around a smooth transition in mean. The model considered are Model (A-C) respectively, where $\varepsilon_{t} \sim N I D(0,1)$. 
For each of the 1000 simulated series the tests $t_{A S}^{A}, t_{A S}^{B}, t_{A S}^{C}, e_{\alpha}, e_{\alpha(\beta)}$ and $e_{\alpha \beta}$ were calculated for the empirical power of the tests at the $5 \%$ and $10 \%$ nominal sizes respectively. The results are given in Table (4). The $K M C-S T R$ has good power overall. While it appears to have similar power to the ESTR when the number of observations is larger, it appears to have slightly more power than the ESTR when the number of observations are smaller. The tests show higher power than the ESTR when persistence is high.

\section{Empirical results}

In our empirical application we use monthly and quarterly nominal exchange rates for seventeen and twenty OECD economies, respectively, and construct bilateral CPIbased real exchange rates against the U.S. dollar and the German mark. The series are obtained from the International Monetary Fund's International Financial Statistics (IFS), which covers the period 1980 to 1998. The data used are nominal exchange rates against US dollar and CPIs (Consumer's Price Index) for both series. This sample period corresponds to a homogeneous regime of the recent floating period. Indeed, by dropping the data before 1980, we exclude the initial turbulent year of the ERM. Furthermore, by ending the sample in 1998, we aim to avoid any contamination in the run up to EMU

We begin with the official real exchange rates and the number of lags, $k$, were determined using the general-to-specific testing strategy at the $10 \%$ level of significance, starting with $k=12$.

\subsection{OECD RER against US dollar}

The tables in this section report the empirical results using the tests for structural break reviewed in section 3 and our proposed modification.

Table (5) shows that the $t_{E S T R}$ cannot reject the unit root null with quarterly data, while the $t_{L S T R}$ rejects the unit root null at the $10 \%$ level for several countries. On the other hand, the $t_{A S}^{A}$ rejects the null hypothesis in more than half of the countries. Figure (5) shows the (quarterly data fitted) smooth transition for $t_{A S}^{A}$, over the sample period 1980:Q1-1998:Q4. It is evident that the asymmetric model fits the data well. We believe these results are supportive of our modeling strategy for quarterly, but not monthly data and this result is different to that reported in Papell (1997). In fact, using panel data tests, he finds more evidence in favor of PPP when monthly rather than quarterly data are used. One possible reason for this finding may be due to the lower frequency data not being able to fully capture structural breaks. 


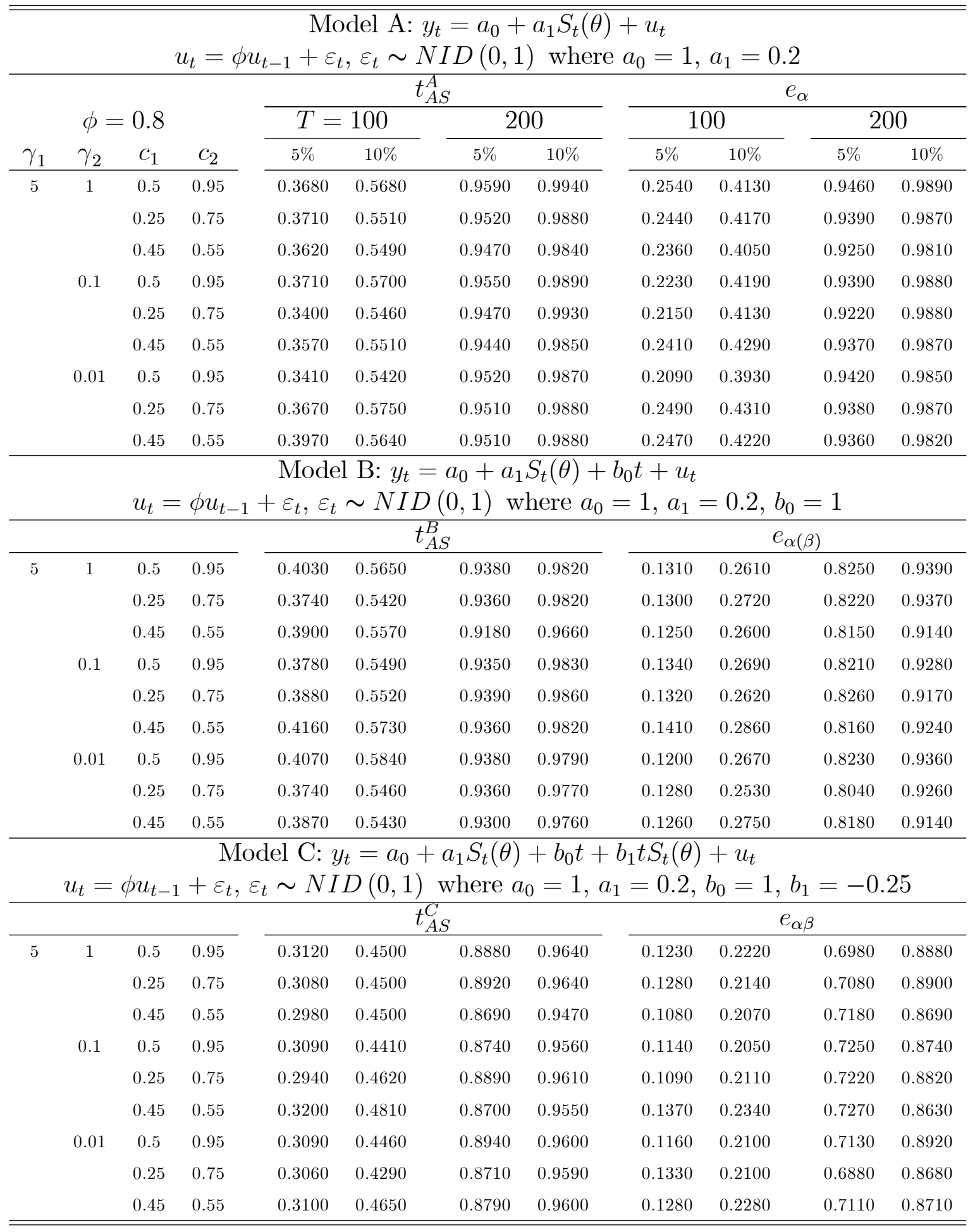

Table 4: Power of Symmetric and Asymmetric KMC-STR for Model A, B and C 


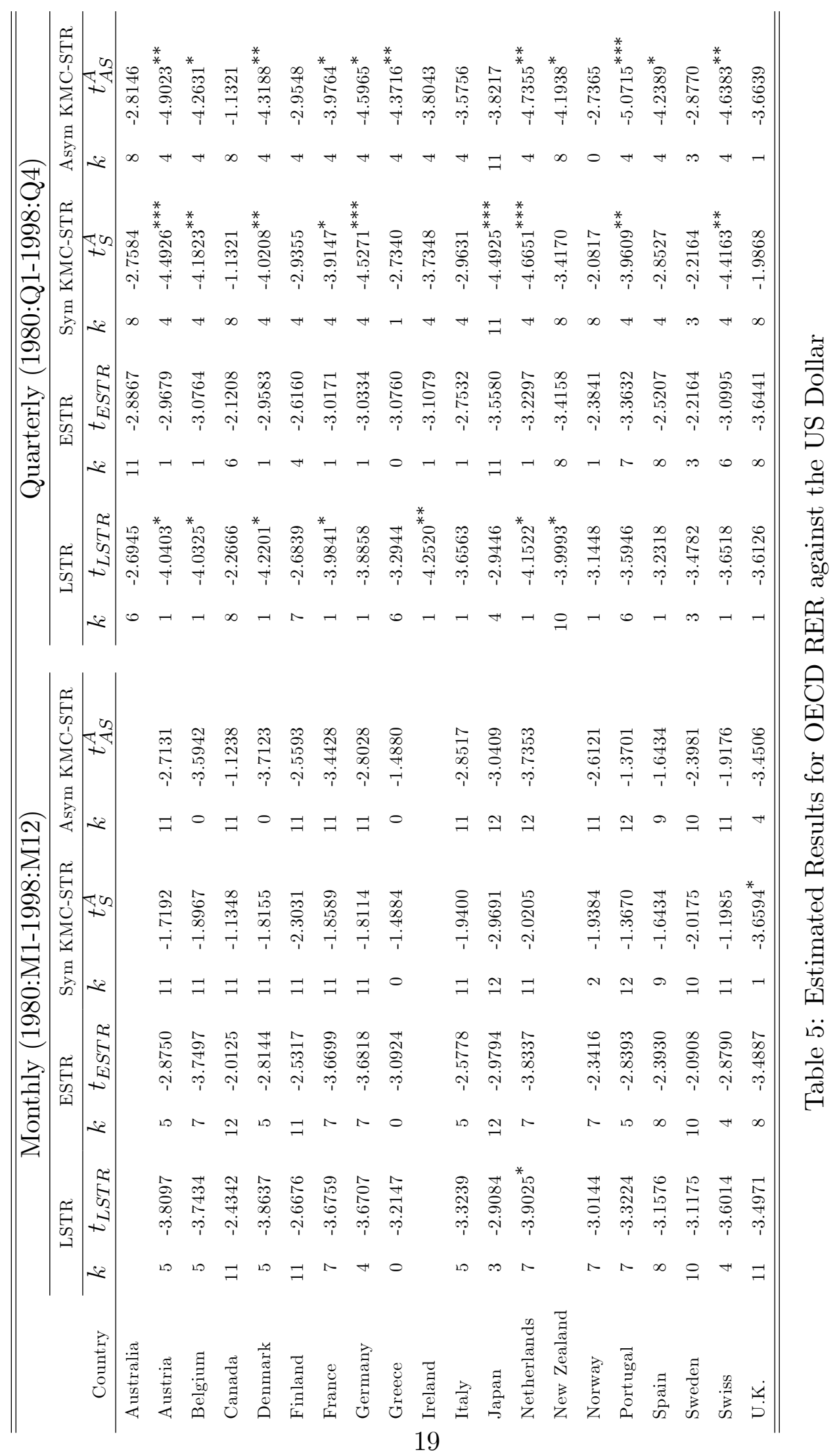



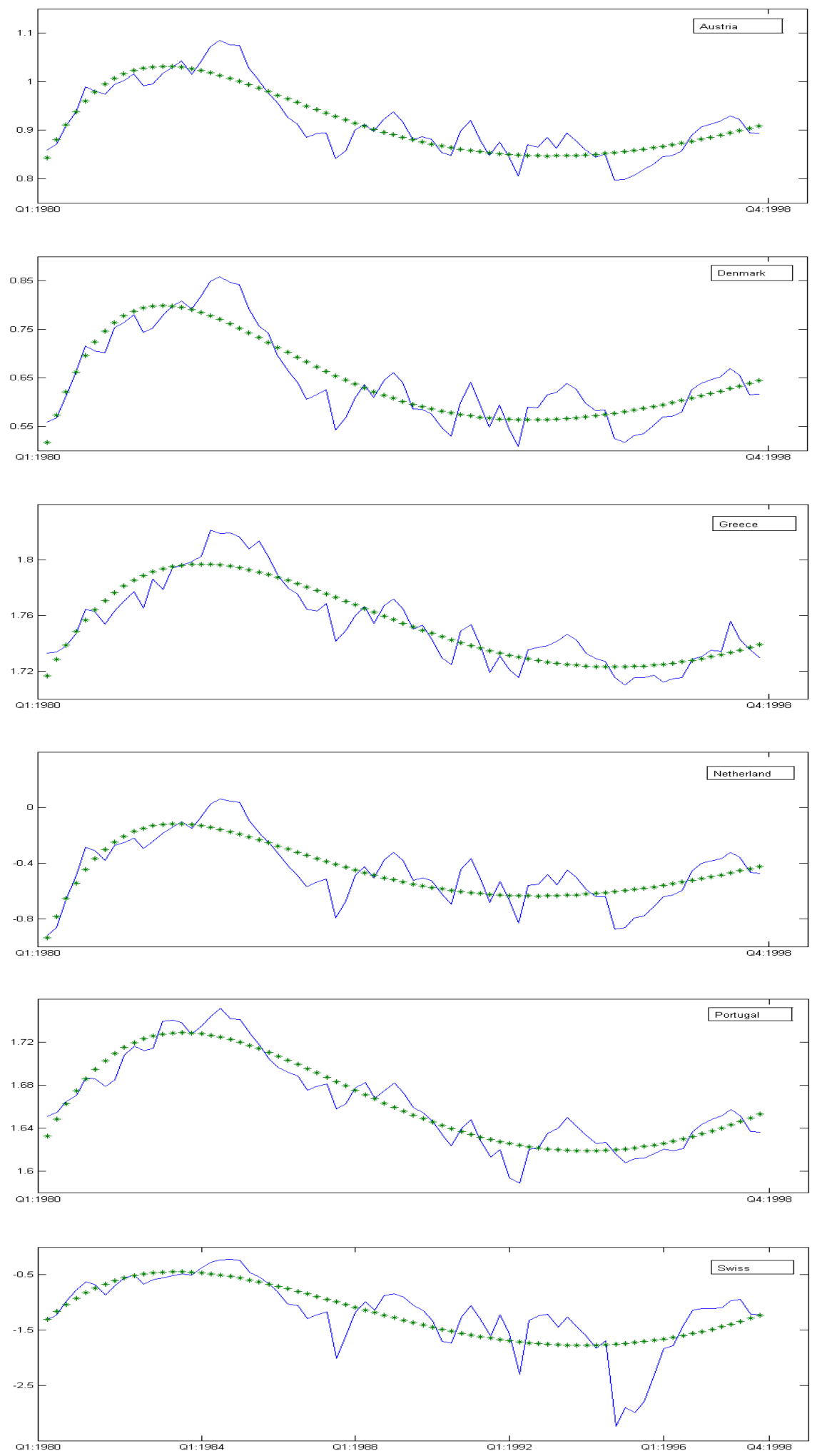

Figure 5: Asymmetric KMC-STR for Quarterly RER against the US dollar 


\subsection{OECD RER against DM}

Jorion and Sweeney (1996), Papell (1997) and Papell (2002) argue that the large appreciation and depreciation of the US Dollar in 1980s introduces a large spike into currencies denominated against the dollar thereby making it more difficult to find evidence of real exchange rate mean reversion.Jorion and Sweeney (1996)points out that more favorable evidence in support of PPP occurs among European countries than those countries relative to the US (i.e. when the U.S Dollar is chosen to be the numeraire currency). Using panel methods he finds more evidence of long-run PPP when the German mark, instead of the U.S. dollar, is used as the base currency. In this section, we construct real exchange rates using the German currency as the numeraire currency to see if our tests produce different results relative to our US dollar based findings.

Interestingly, we find here that the ESTR and LSTR put in a better performance relative to the US based results and our own statistics, although still producing rejections of the null, are not as strong as when the US dollar is the numeraire. Figure (6) shows the (quarterly data fitted) smooth transition for $t_{A S}^{A}$, over the sample period 1980:Q1-1998:Q4. It is again evident that the asymmetric model fits the data well.

Thus, overall we find that using our asymmetric transition function we can detect more evidence of stationarity in real exchange rates than other structural changes models when both the US Dollar and the German Mark are used as numeraire currencies, although the evidence is stronger for the former and so our test would seem to provide an ideal way of addressing the large spike in the US dollar in the 1980's. Furthermore, and in contrast to other empirical studies (see for example Papell (2002)), we find more evidence of PPP when quarterly, rather than monthly, data are used.

\section{Conclusion}

In this paper we have examined the determination of the equilibrium real exchange rate in the presence of structural change. In particular, we propose an equilibrium exchange rate model with a risk premium and a stationary component, resulting from non-fundamental trading behaviour, to motivate structural changes. Additionally, the paper proposed a novel transition function which is capable of mimicing the behavior of the exchange rate model.

We provided an empirical application based on monthly and quarterly real exchange rate data and two numeraire currencies, the US dollar and the German mark and we show that once we incorporate structural breaks, evidence of stationarity in real exchange rates increases. Additionally, we show that evidence in favor of a stationary real exchange rate is much stronger when quarterly rather than monthly data are used.

The paper also considered German mark-based real exchange rates and the empirical results are in line with the literature and show that there is stronger evidence in favour of stationarity across the range of tests considered in this paper, although the new tests proposed here work best for the US dollar. 


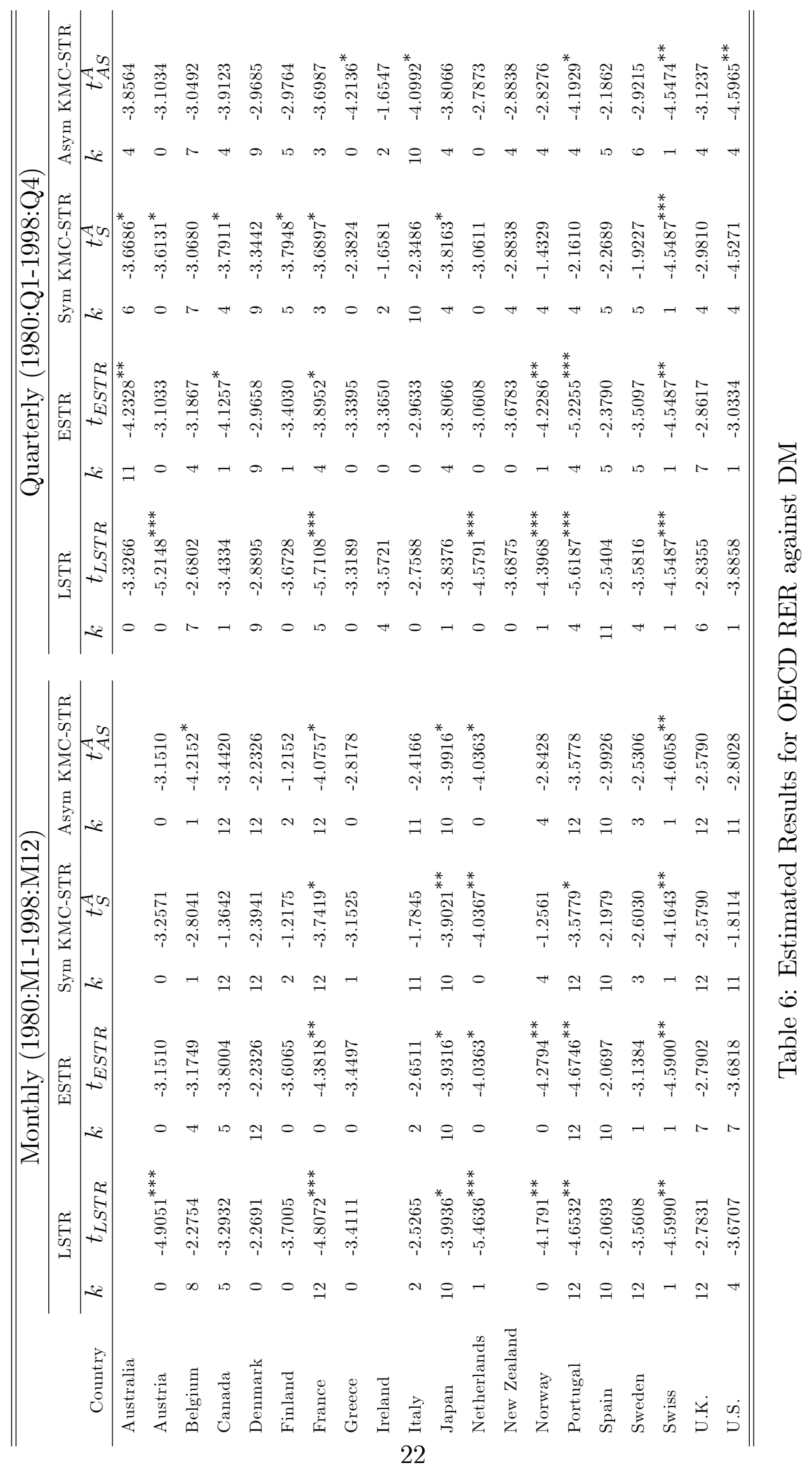



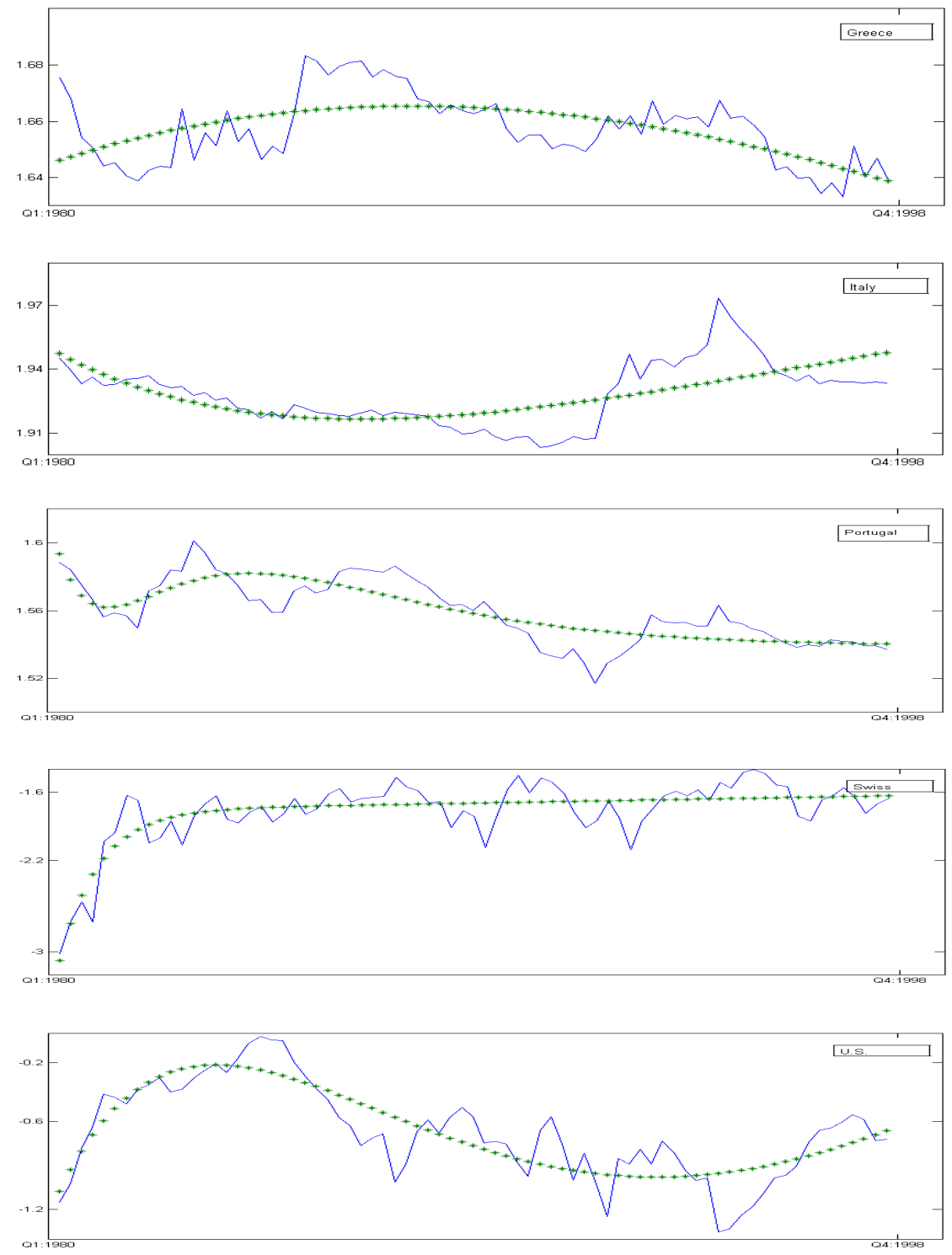

Figure 6: Asymmetric KMC-STR for Quarterly RER against the DM mark 


\section{References}

Abauf, N. and P. Jurion (1990). Purchasing power parity in the long run. The Journal of Finance 45(1), 157-74.

Bleaney, M. and S. J. Leybourne (2003). Real exchange rate dynamics under the current float: A re-examination. The Manchester School 71, 156-171.

Caner, M. and B. E. Hansen (2001). Threshold autoregression with a unit root. Econometrica 69(6), 1555-96.

Chow, G. C. (1960). Tests of equality between sets of coefficients in two linear regressions. Econometrica 28(3), 591-605.

Christopher F. Baum, J. T. B. and M. Caglayan (1999). Long memory or structural breaks: Can either explain nonstationary real exchange rates under the current float? Journal of International Financial Markets, Institutions and Money 9, 359-376.

Clark, P. B. and R. MacDonald (1998). Exchange rates and economic fundamentals: A methodological comparison of BEERs and FEERs. IMF Working Paper 6\%.

Davies, R. B. (1987). Hypothesis testing when a nuisance parameter is present only under the alternative. Biometrika 74 (1), 33-43.

Dijk, V., D. T. Terasvirta, and P. Franses (2002). Smooth transition autoregressive models: A survey of recent developments. Econometric Reviews 21, 1-47.

Dutta, J. and H. Leon (2002). Dread of depreciation: Measuring real exchange rate interventions. IMF Working Paper 63.

Frankel, J. A. and A. K. Rose (1996). Currency crashes in emerging markets: An empirical treatment. Journal of International Economics 41(3-4), 351-366.

Jorion, P. and R. Sweeney (1996). Mean reversion in real exchange rates: Evidence and implications for forecasting. Journal of Money and Finance 15, 535-50.

Leybourne, S. J., P. Newbold, and D. Vougas (1998). Unit roots and smooth transitions. Journal of Time Series Analysis 19, 83-97.

Lyons, R. K. (1999). The Microstructure Approach to Exchange Rates. Cambridge, Mass: MIT Press.

MacDonald, R. (1996). Panel unit root tests and real exchange rates. Economics Letters 50, 7-11.

MacDonald, R. (2007). Exchange Rate Economics: Theories and Evidence. Routledge.

Nelder, J. A. (1971). The fitting of a generalisation of the logistic curve. Biometrics $17,89-110$. 
Nelson, C. and C. Plosser (1982). Trend and random walks in macroeconomics time series: Some evidence and implications. Journal of Monetary Economics 10, 139 162.

O'Connell, P. G. J. (1998). The overvaluation of purchasing power parity. Journal of International Economics 44, 1-19.

Oh, K.-Y. (1996). Purchasing power parity and unit root tests using panel data. Jouranl of International Money and Finance 15, 405-18.

Papell, D. H. (1997). Searching for stationarity: Purchasing power parity under the current float. Journal of International Economics 43, 313-332.

Papell, D. H. (2002). The great appreciation, the great depreciation, and the purchasing power parity hypothesis. Journal of International Economics 5\%, 51-82.

Perron, P. (1989). The great crash, the oil price shock and the unit root hypothesis. Econometrica 5\%, 1361-1401.

Rogoff, K. (1996). The purchasing power parity puzzle. Journal of Economic Literature 34, 647-68.

Sollis, R. (2005). Evidence on purchasing power parity from univeriate models: The case of smooth transition trend-stationarity. Journal of Applied Econometrics 20, $79-98$.

Sollis, R., S. J. Leybourne, and P. Newbold (2002). Tests for symmetric and asymmetric nonlinear mean reversion in real exchange rates. Journal of Money, Credit and Banking $34(3), 686-700$.

Wu, Y. (1996). Are real exchange rates nonstationary? evidence from a panel data test. Journal of Money, Credit and Banking 28, 54-63.

Zivot, E. and D. W. K. Andrews (1992). Further evidence on the great crash, the oil-price shock, and the unit-root hypothesis. Journal of Business and Economic Statistics 10, 251-270. 